\title{
CFD Simulation of a DME Fuelled CI Engine
}

\author{
Gaurav Mittal, Jasmeet Kalra
}

Abstract: A computational study is conducted for a DME fuelled CI engine of $373.3 \quad \mathrm{~cm}^{3}$ displacement and 17.8 compression ratio at moderate load with detailed chemistry. Due to the symmetry of the cylinder, the simulations are conducted on a sector of the cylinder, from the closing of intake valve to the opening of exhaust valve. In the pilot injection strategy employed, $10 \%$ of the total fuel is injected during the pilot injection and the balance in the main injection at $5^{0}$ BTDC. The computational model is first validated using the experimental data. Results show two-stage ignition characteristic for the DME injected in the pilot injection.

\section{Keywords: DME, CFD simulation, pilot injection}

\section{INTRODUCTION}

Dimethyl Ether (DME) is recognized as a clean alternative to petroleum derived diesel fuel. With DME there is no particulate matter (PM) formation due to the lack of C-C direct bond. In compression ignition engines, DME performance may be superior to diesel and engine operation is less noisy. Its high vapour pressure leads to reduction in wall-wetting [1]. A high cetane number of around 55 and a low boiling temperature of $-25{ }^{\circ} \mathrm{C}$ provides rapid mixing, decreased ignition delay, and outstanding cold starting characteristics. The potential of DME fuelled CI engines has been explored by a number of researchers, for example [19].

Use of multiple injections, in which more than one injections are employed every cycle, have been shown to be a potential means for mitigating emission of pollutants from CI engines. In a pilot injection, less than $10 \%$ fuel is injected in the first injection. Pilot and split injection can be effective in concurrently reducing soot and $\mathrm{NO}_{\mathrm{x}}$ from $\mathrm{CI}$ engines. By using DME in CI engines there is no soot formation, and by using multiple injection strategy, $\mathrm{NO}_{\mathrm{x}}$ formation can potentially be reduced.In this work, combustion inside a DME fuelled CI engine is studied computationally. In the following, the computational specifications are provided, followed by a discussion of results.

\section{COMPUTATIONAL SPECIFICATIONS AND VALIDATION}

The computational model was developed using the Converge CFD code. Simulations employed RNG $\mathrm{k}-\varepsilon$ turbulence model and KH-RTspray models. O'Rourke collision model was employed for droplet collision, whereas Frossling model was used for evaporation. The drop/wall interactions were modelled using the wall film model.
Experimental and numerical studies of Kim et al. [1,2] were selected for computational validation. The engine had a bore of $75 \mathrm{~mm}$, stroke of $84.5 \mathrm{~mm}$, compression ratio of 17.8 , and 6 hole injector with $0.128 \mathrm{~mm}$ hole diameter. IVC and EVO occurred at $128^{\circ} \mathrm{BTDC} 172^{0}$ ATDC respectively. For validation, an engine running at $1500 \mathrm{rpm}$ and swirl ratio of 1.63 was modelled. DME injection pressure was $50 \mathrm{MPa}$. Mass of the fuel injected into each injector per cycle was $1.33 \mathrm{mg}$.

As there are six injection nozzles or holes, the engine can be divided into six sectors, each of $60^{\circ}$. Due to the symmetry of the combustion chamber, the CFD simulations were conducted on a $60^{\circ}$ sector mesh. Simulations were run from IVC to EVO. The CFD code used a structured Cartesian grid having a base cell of $1.0 \mathrm{~mm}$. Adaptive mesh refinements in the region of large gradients and fixed embedding in the spray region were also employed. The kinetic model for DME by Zhao et al. [10]was employed for the present study. It has 55 species and 290 reactions and has been well validated over a broad range of temperatures and pressures relevant to engines.

The engine sector along with the mesh is shown in Figure 1. The initial gas temperature inside the cylinder at intake valve closure (IVC) was $320 \mathrm{~K}$ and initial pressure was $1.07825 \mathrm{~atm}$. The temperature at piston, head, and cylinder walls was specified as $550 \mathrm{~K}, 520 \mathrm{~K}$ and $430 \mathrm{~K}$ respectively. Based on [1,2] the start of pilot injection timing was selected as $20^{\circ}$ BTDC for validation. The duration of injection was estimated from the spray penetration curve or injection rate curve $[1,2]$.

The results from the validation study are compared against the experimental data from [1,2] in Figure 2. An excellent agreement is noted between the experiment and simulation during the compression and expansion stroke as well as in the peak pressure and combustion phasing. Since the chemical kinetic mechanism used here was already comprehensively validated, the agreement in the engine pressure traces may be taken as a sufficient evidence of the suitability of the present engine model for predictive simulations.
Revised Manuscript Received on April 25, 2019.

Gaurav Mittal (Corresponding author), Department of Mechanical Engineering, Graphic Era Deemed to be University, Dehradun, India. Email: gauravmittal@geu.ac.in

Jasmeet Kalra, Department of Mechanical Engineering, Graphic Era Hill University, Dehradun, India 

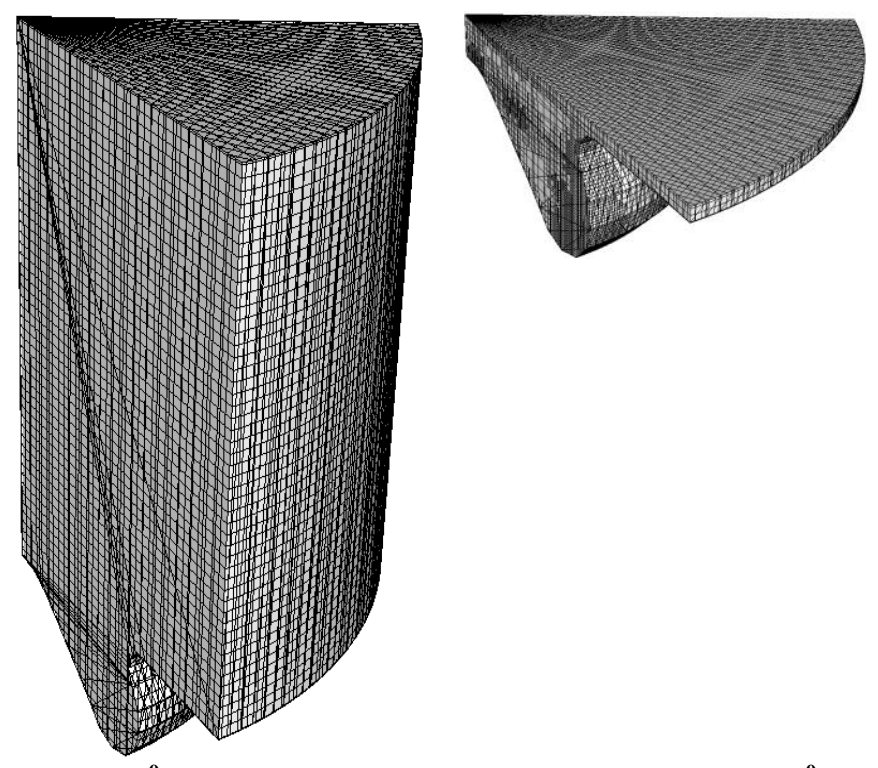

a. $87.9^{0}$ BTDC
ATDC

Figure 1 - Computational mesh

\section{RESULTS}

In the pilot injection strategy, only $10 \%$ of fuel was supplied during the first pulse of injection at $40^{\circ} \mathrm{BTDC}$ and the balance $90 \%$ during the main injection at $5^{\circ} \mathrm{BTDC}$. The numerical conditions are specified in Table 1. Engine specifications have already been detailed.

\begin{tabular}{cc} 
Table 1 - Numerical conditions of DME fuelled engine \\
\hline Engine speed (rpm) & 1500 \\
Initial temperature (K) & 320 \\
Initial pressure (atm) & 1.74 \\
Injection pressure (MPa) & 60 \\
Mass of fuel injected(mg/cycle) & 26 \\
Injection fuel temperature (K) & 300 \\
\hline
\end{tabular}

Figure 3 shows pressure curve of a reactive cycle as well as the motored pressure trace. The difference between the two pressure traces indicates the extent of energy released from combustion. From the pressure traces, it is evident that there is significant heat release from the pilot injection even before the onset of the primary injection. The heat release rate curve is shown in Figure 4. The initial peak in the heat release is around $15^{\circ} \mathrm{BTDC}$, followed by a lower peak before the main injection. Both of these peaks are due to combustion of the pilot injection. Combustion of the main injection is noted only after TDC. An important aspect is to understand the manner in which the combustion of the pilot charge modifies the in-cylinder temperature and concentration at the instant of main injection.

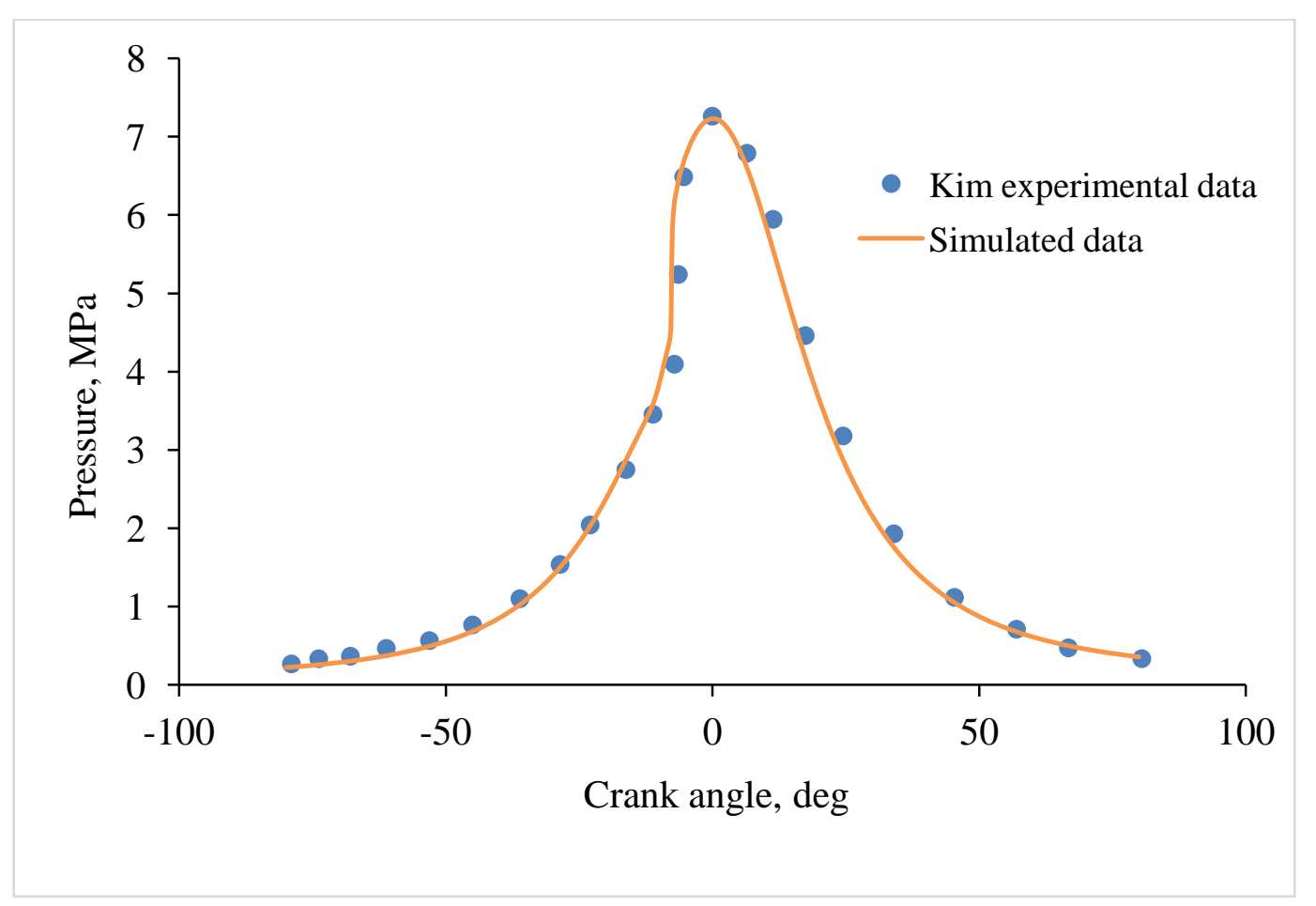

Figure 2-Comparison of simulation with experimental result from [1,2].

The reason for the two distinct heat release curves for pilot injection is temporal separation of the first and second stage heat release. The concentrations of formaldehyde, DME, and $\mathrm{CO}$ are shown in Figure 5. The concentrations in Figure 5 are scaled for clarity. From these plots, it is clear that the first peak in heat release at $15^{0}$ BTDC is due to the first stage ignition of the pilot injection. During this phase, significant amount of formaldehyde is produced due to low temperature reactions involving peroxidation. Furthermore, the rise in maximum temperature at this time is small and the peak temperature remains less than $1000 \mathrm{~K}$ even after the first peak in heat release. Following the first stage ignition, the peak temperature reaches $2500 \mathrm{~K}$ at around $11^{\circ}$ BTDC, which is followed by a second, smaller peak in the heat release. This indicates that the second peak in heat release is due to the second stage or hot ignition during which combustion in the part of the domain goes to completion. 


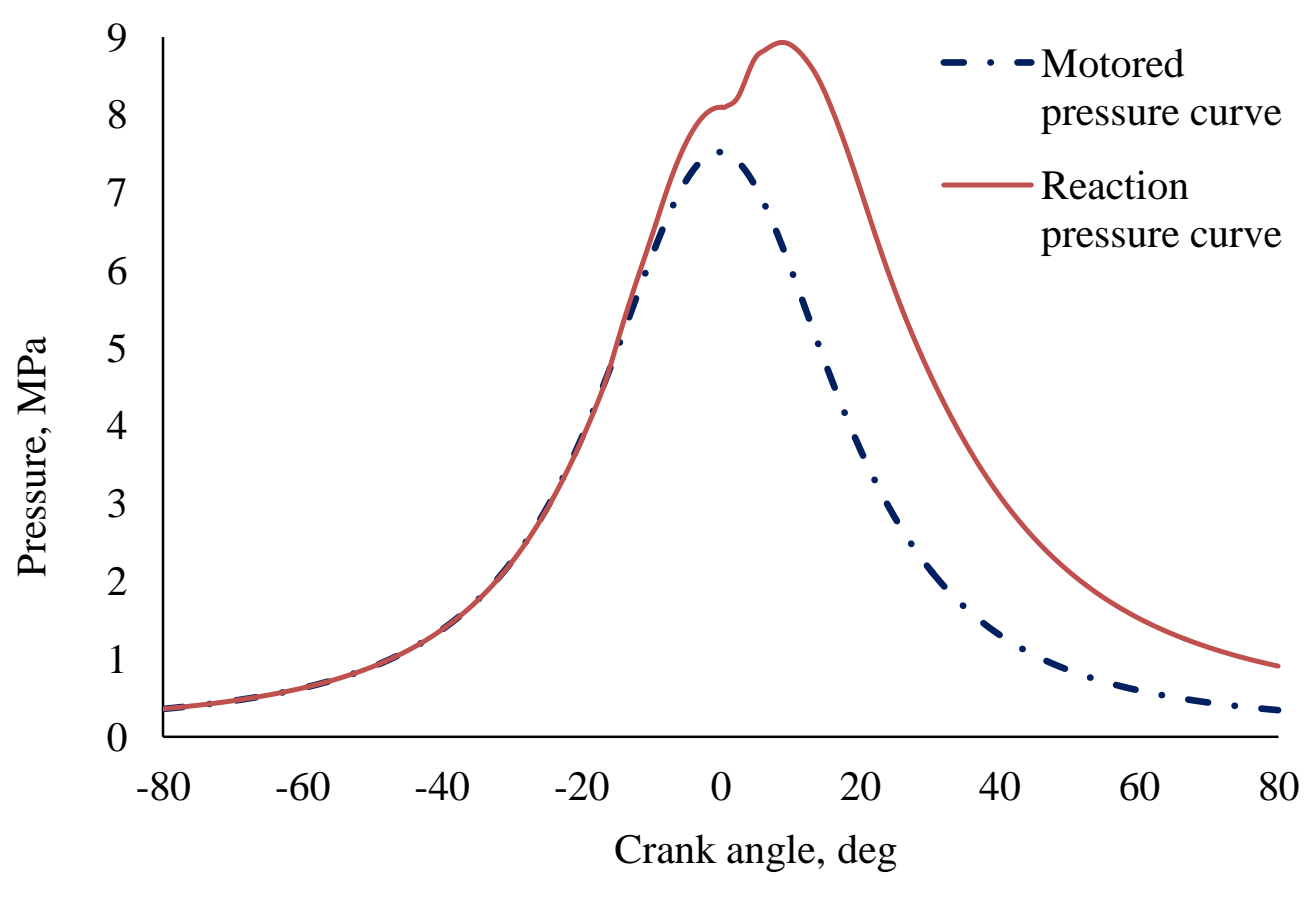

Figure 3 - Pressure curves

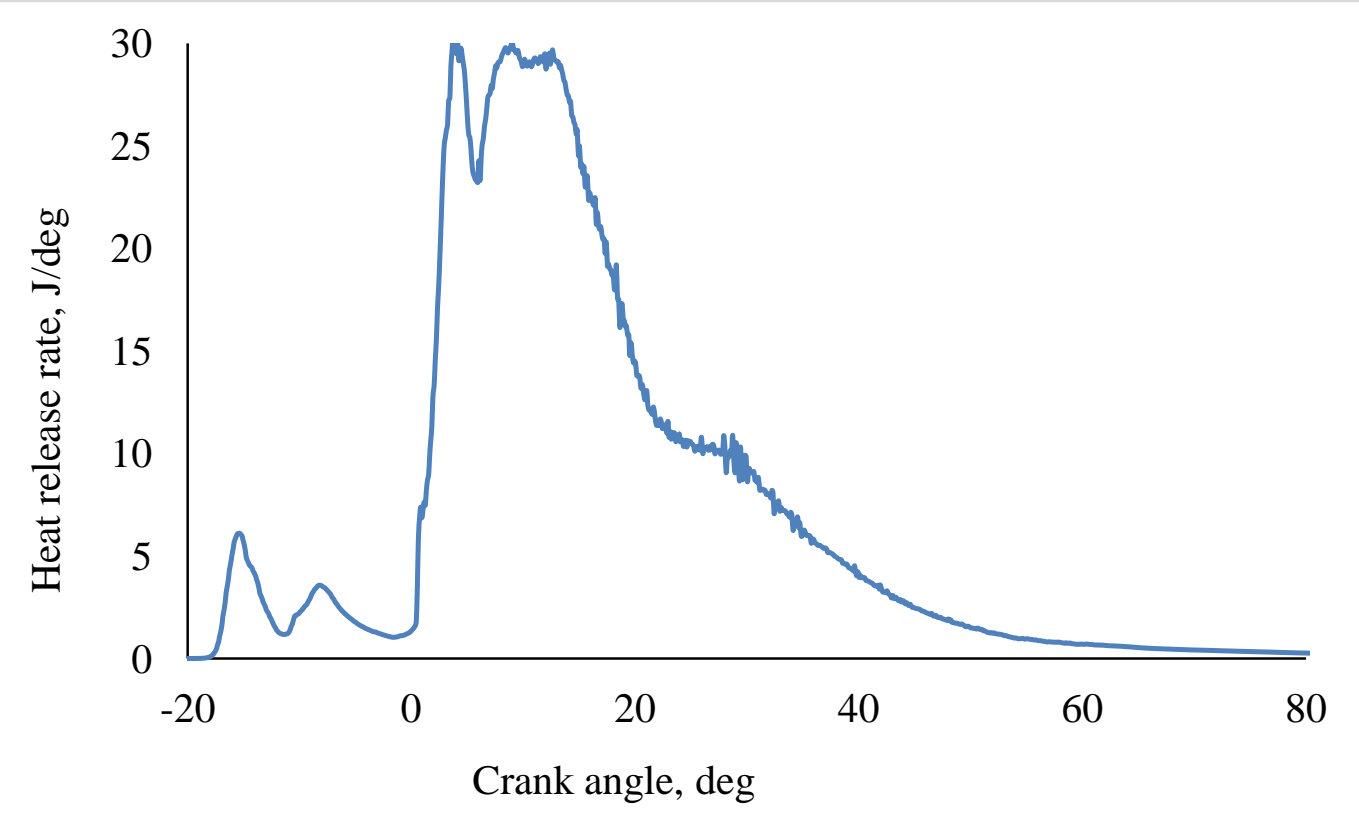

Figure 4 - Heat release rate for pilot injection at $40^{\circ}$ BTDC and main injection at $5^{\circ}$ BTDC

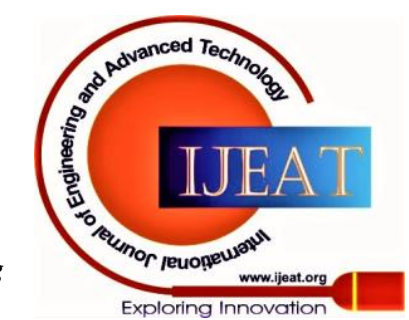




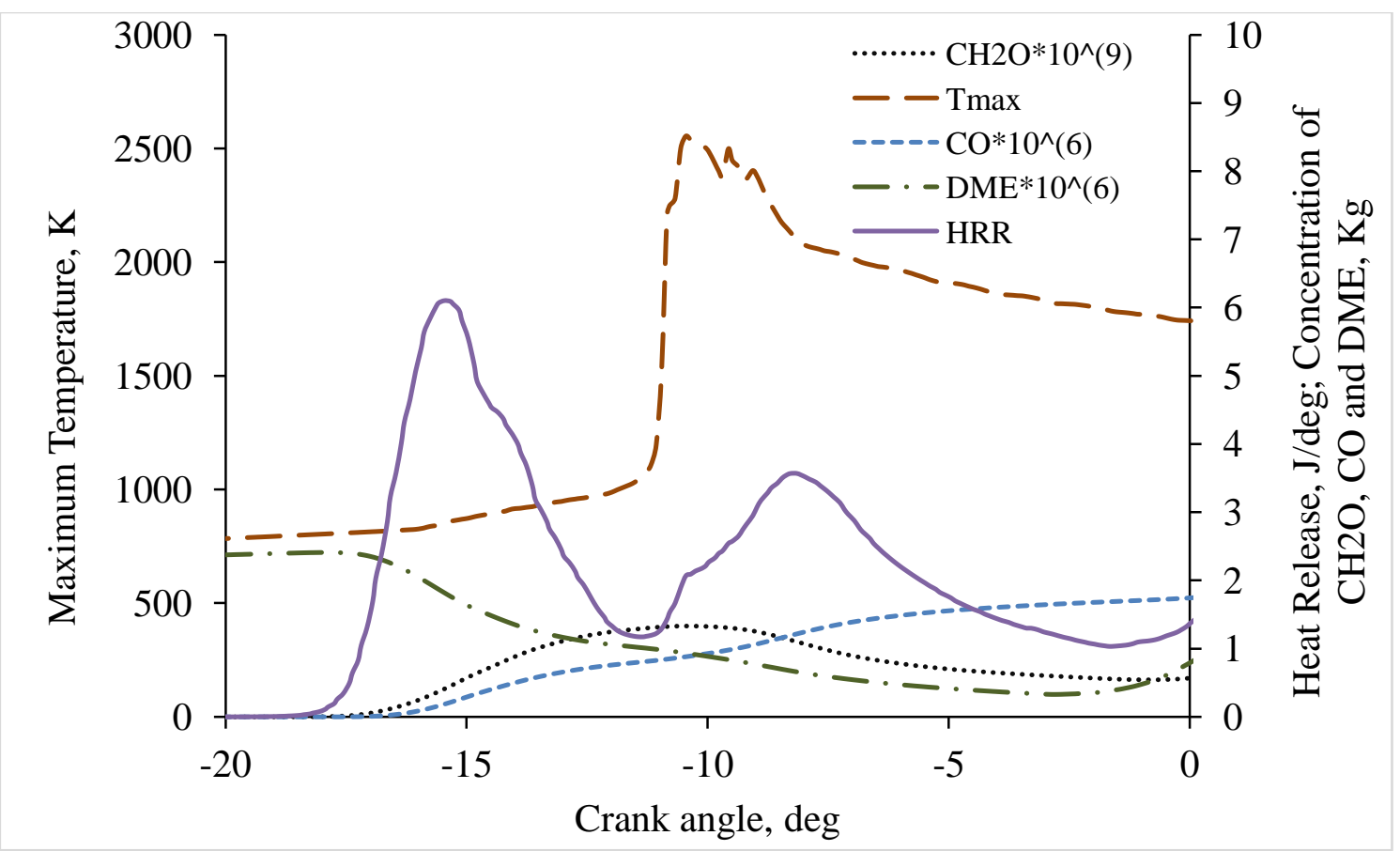

Figure 5 - HRR, formaldehyde, CO, DME concentrations and maximum temperature

The second stage ignition is, however, highly nonuniform and occurs only in part of the domain. This is based on the observation that the concentration of $\mathrm{CO}$ remains significant as well as formaldehyde persists. Persistence of these species is a clear indication that some regions in the domain are over-mixed and do not allow for the second stage ignition to occur. It has important implications for emissions as the $\mathrm{CO}$ and $\mathrm{HC}$ in the over-mixed region, which did not undergo hot ignition, might not burn even during the main injection and may lead to engine out $\mathrm{CO}$ and $\mathrm{HC}$ emissions.

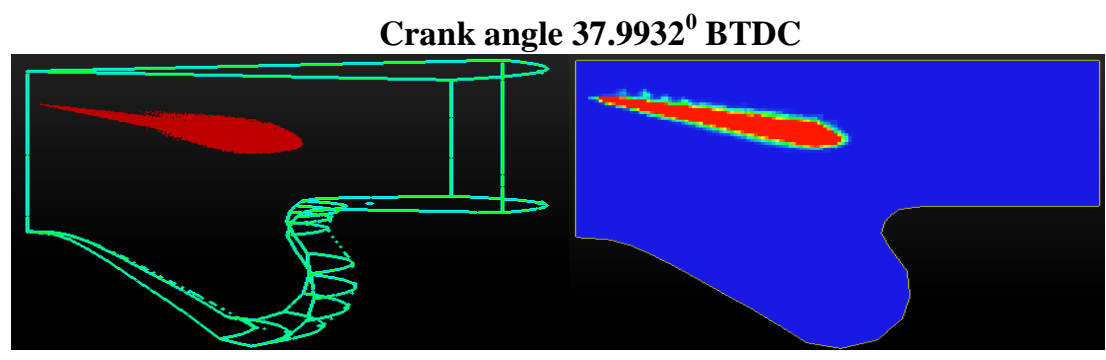

Crank angle 29.95920 BTDC

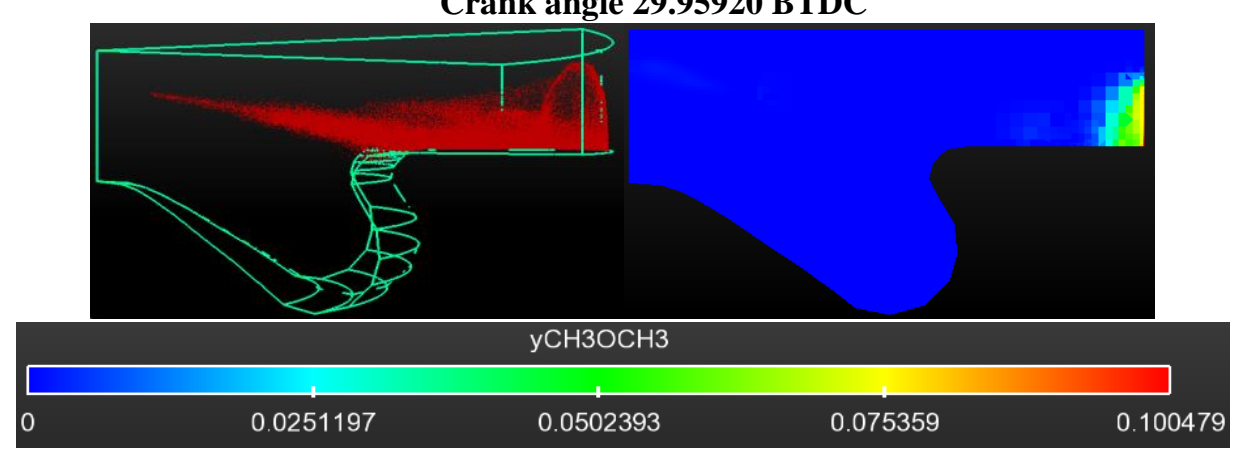

Figure 6 - Spray penetration and spray vaporization in the cylinder after the pilot injection at 400 BTDC

The heat release following main injection, Figure 4, is typical of diesel combustion where a premixed burning phase is followed by the mixing controlled combustion as spray continues. The premixed burning phase here, however, has only one peak as the cylinder temperature is high and the first stage and hot ignition are not temporally separated.Spray penetration and DME vapour mass fractions following pilot injection and main injection are shown in Figures6 and 7, respectively. The pilot injection is targeted in the squish region. The larger and colder droplets are closer to the injector. As they travel away from the injector, they are broken down and evaporated due to the rise in the temperature by absorption of heat and finally the fuel gets converted from liquid state to gaseous state.

In Figure 6, DME vapours are observed only close to the wall. This is, however, misleading because the mass fraction shown is only in the plane of injection;

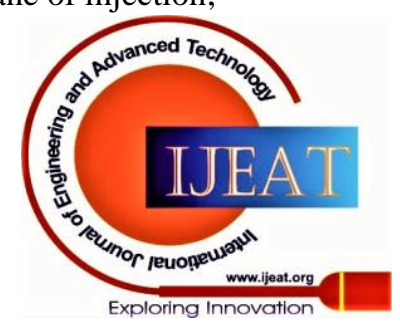


whereas, DME vapours are convected in the direction of swirl. Before the main injection, all the fuel injected during pilot injection mixes completely with the gas present in the cylinder. Main injection starts at $5^{0}$ BTDC.
The main injection is targeted in the bowl where it burns as also noted by temperature fields shown in Figure 8. Since the first injection is targeted in the squish, which may not be ideal, additional studies could be conducted by changing the spray umbrella angle.

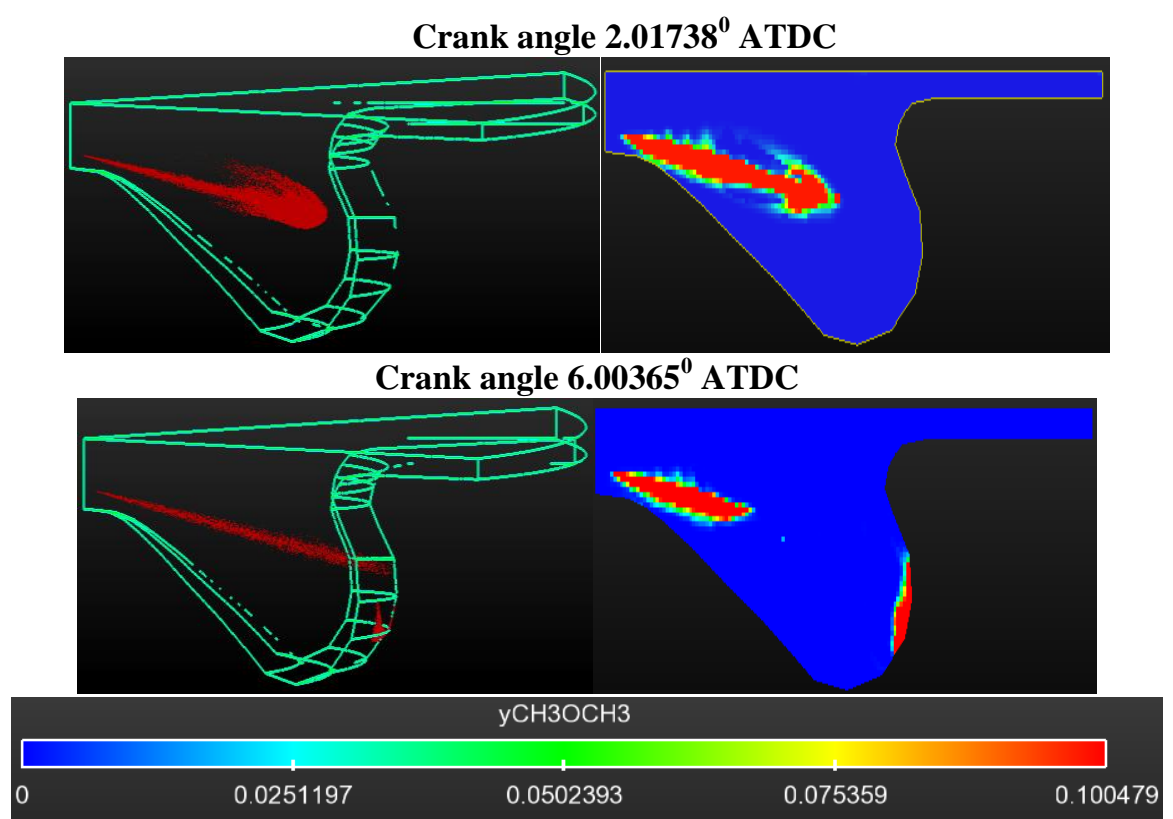

Figure 7 - Spray penetration and vaporization inside the cylinder after the main injection.

\section{CONCLUDING REMARKS}

DME fuelled CI engine was studied computationally after validating with experimental data. Simulation was conducted for a pilot injection strategy in which $10 \%$ fuel was injected as pilot and $90 \%$ as main injection. Simulations show distinct two-stage ignition of pilot fuel. However, pilot injection at $40^{\circ} \mathrm{BTDC}$ leads to some over-mixed regions in which the hot ignition does not go to completion. This observation has implications for $\mathrm{CO}$ and $\mathrm{HC}$ formation. In addition, the pilot injection occurred in the squish region. Further studies should be conducted by varying the timing of pilot injection as well as the injector umbrella angle to optimize efficiency and minimize pollutants.
Crank angle $7.98537^{\circ}$ BTDC

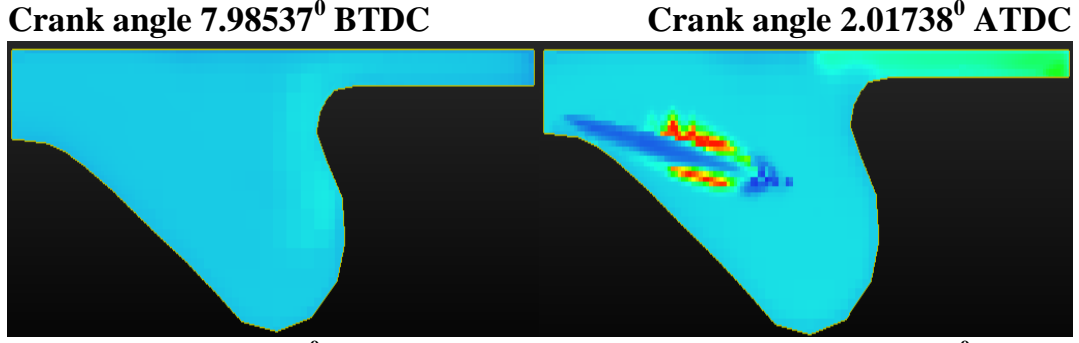

Crank angle $12.0096^{\circ}$ ATDC

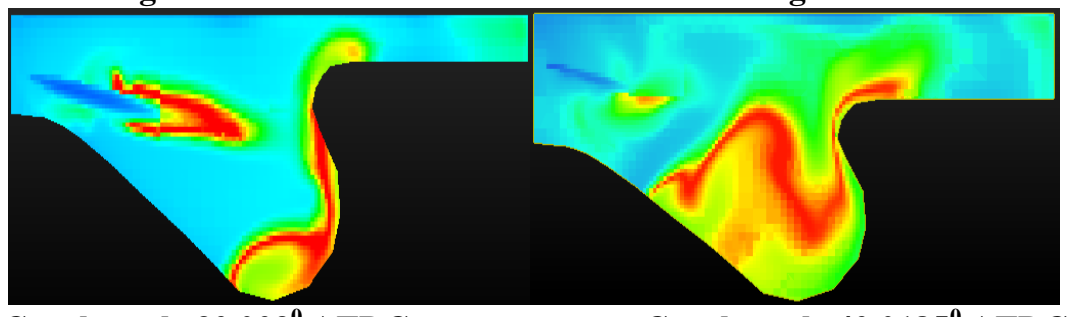

Crank angle $32.023^{0}$ ATDC
Crank angle $42.0185^{\circ}$ ATDC

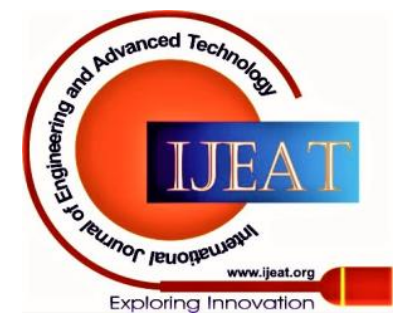




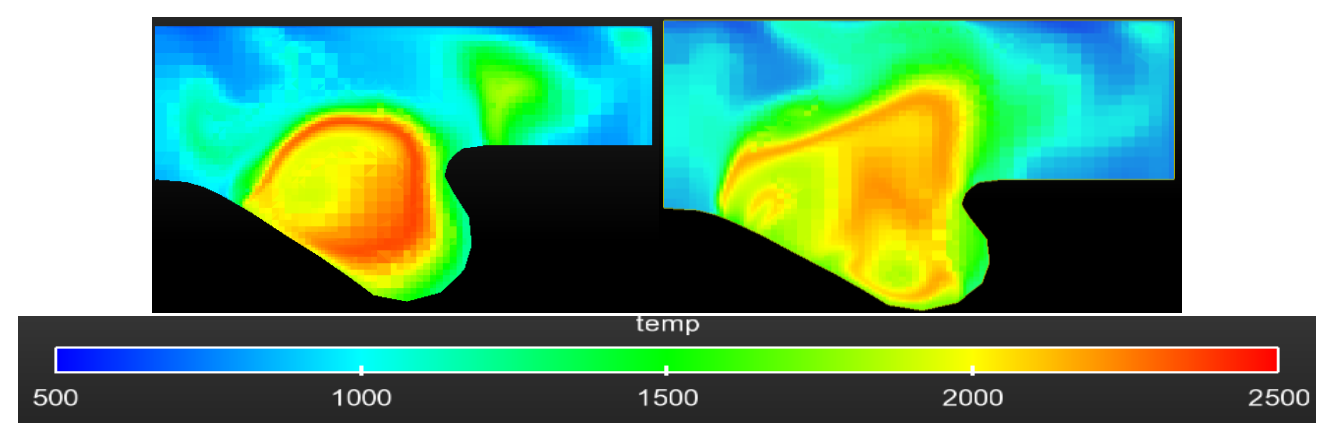

Figure 8 - Temperature distribution $(K)$ inside the cylinder after pilot injection

\section{REFERENCES}

1. Kim, H.J., Park, S.H., Chon, M.S., and Lee, C.S. (2010) A Comparison of Effect of Ambient Pressure on the Atomization of Soybean Oil Methyl Ester and Dimethyl Ether Sprays. Oil Gas Sci Technol, 65(6):883-92.

2. Kim, M.Y., Bang, S.H., and Lee, C.S. (2007) Experimental Investigation of Spray and Combustion Characteristics of Dimethyl Ether in a Common Rail Diesel Engine. Energy Fuel, 21: 793-800.

3. Arcoumanis, C., Bae, C., Crookes, R., and Kinoshita, E. (2008) The Potential of Di-Methyl Ether (DME) as an Alternative Fuel for Compression-Ignition Engines: a Review. Fuel 87, 1014-30.

4. Brandon Borgna, Volvo Trucks and Safeway to Test Bio-DMEPowered Vehicles in North America. June 6, 2013 http://www.volvotrucks.com/trucks/na/en-us/_layouts/CWP.Internet. VolvoCom/NewsItem.aspx?News.ItemId=143306\#sthash.wJhuObKw .dpuf.

5. Khunaphan, S., Hartley, U.W., and Theinnoi, K. (2013) Characterization and Potential of Dimethyl ether (DME) as Dual Fuel Combustion in a Compression Ignition Engine'. IJESIT, Volume 2, Issue 3, pp. 79-85.

6. Thomas, G., Feng, B., Veeraragavan, A., Cleary, M.J., and Drinan, N. (2014) Emissions from DME combustion in diesel engines and their implications on meeting future emission norms: review. Fuel Processing Technology, 119:286-304.

7. Wang, Y., and Zhou, L. (2007) Performance and Emissions of a Compression-Ignition Engine Fueled with Dimethyl Ether and Rapeseed Oil Blends. Energy Fuel, 21(3), 1454-8.

8. Yu, Y., Kang, S., Kim, Y., and Lee, K.S. (2009) Numerical Study on Spray Combustion in n-Heptane and DME Fueled Diesel Engine. Energy \& Fuels 2009, 23, 4917-4930.

9. Song, R., Li, K., Feng, Y., and Liu, S. (2009) 'Performance and Emissions Characteristics of DME Engine with High Ratio of EGR'. Energy \& Fuels, 23, 5460-5466.

10. Zhao, Z., Chaos, M., Kazakov, A., and Dryer, F.L. (2008) Thermal Decomposition Reaction and a Comprehensive Kinetic Model of Dimethyl Ether, Int. J. Chem. Kinet., 40, 1-18. 